\title{
Sciendo
}

\section{Logical Determinacy versus Logical Contingency. The Case of Lukasiewicz's Three-valued Logic}

\author{
Andrew Schumann \\ University of Information Technology \\ and Management in Rzeszow, \\ Sucharskiego 2 Street, \\ 35-225 Rzeszow, Poland \\ e-mail: andrew.schumann@gmail.com
}

\begin{abstract}
:
In constructing the three-valued logic, Jan Łukasiewicz was highly inspirited by the Aristotelian idea of logical contingency. Nevertheless, we can construct a four-valued logic for explicating the Stoic idea of logical determinacy. In this system, we have the following truth values: 0 ('possibly false), 1 ('necessarily false'), 2 ('possibly true'), 3 ('necessarily true'), where the designated truth value is represented by the two values: 2 and 3 .

Keywords: Łukasiewicz, many-valued logic, three-valued logic, modal logic, four-value logic, logical contingency, logical determinacy.
\end{abstract}

\section{Introduction}

There are two extreme approaches to modalities: logical contingency and logical determinacy. According to the first approach, there exist contingent events $A$ which are possible to be and possible not to be simultaneously: ' $A$ is possible and non- $A$ is possible'. This approach was formulated by Aristotle for the first time. The second approach is a negation of the first one: 'Either $A$ is necessary or non- $A$ is necessary'. According to this claim, each event is either necessarily to be or necessarily not to be. At first, it was formulated by the Stoics.

In this paper, I show that the modal logics $\mathbf{D}$ and $\mathbf{T}$ help to formalize the Aristotelian approach (Section 2) and the modal logics $\mathbf{C D}$ and $\mathbf{K}=$ formalize the Stoic approach (Section 3). Łukasiewicz proposed his system of three-valued logic as his own attempt to justify the Aristotelean idea of logical contingency (Section 4). Nevertheless, we can propose a four-valued logic to justify the Stoic idea of logical determinacy (Section 5). This logic is proposed for the first time.

\section{Modal Logic for Logical Contingency}

The vocabulary of modal logic is as follows:

- $p_{0}, p_{1}, \ldots$ - propositional atoms, Prop; 
- $\neg, \vee, \wedge, \Rightarrow, \Leftrightarrow-$ propositional connectives: negation (“not...”), disjunction (“... or ...”), conjunction ("... and ..."), implication (if... , then, ..."), equivalence (“... if and only if..."), respectively;

- $\square, \diamond-$ modal operators: the symbol $\square$ is used for "necessity' (“... is necessarily") and the symbol $\diamond$ is for 'possibility' (“... is possibly”).

On the basis of this vocabulary, we can define well-formed formulas:

- Each propositional atom from Prop is a formula;

- If $A$ and $B$ are formulas, then $\neg A, \neg B, A \vee B, A \wedge B, A \Rightarrow B, A \Leftrightarrow B, \square A, \square B, \diamond A, \diamond B$ are formulas, as well.

The meanings of well-formed formulas without modal operators are defined in a standard way within the two-valued logic, about the meanings of modal formulas please see [2].

The basic modal logic, denoted by $\mathbf{K}$ in honor of Soul Kripke, has the following axioms:

- All propositional axioms such as $A \vee \neg A$;

- All instances of the Kripke schema: $\square(A \Rightarrow B) \Rightarrow(\square A \Rightarrow \square B)$.

The set of these axioms is closed under the following two inference rules:

- modus ponens: from $A \Rightarrow B$ and $A$ it follows that $B$;

- Necessitation rule: if $A$ is an axiom, then $\square A$ is an axiom, too.

On the basis of $\mathbf{K}$, we can obtain two additional systems of modal logic for logical contingency by adding to $\mathbf{K}$ the following two schemas [2]:

(D) $\square A \Rightarrow \diamond A$

(T) $\square A \Rightarrow A$

If we add to $\mathbf{K}$ all the instances of (D), then the new modal logic is denoted by $\mathbf{D}$. In the meanwhile, if we add to $\mathbf{K}$ all the instances of $(\mathrm{T})$, then the new modal logic is denoted by $\mathbf{T}$. Let us notice that all the axioms of $\mathbf{D}$ are contained in the class of axioms of $\mathbf{T}$. For the first time, the intuition of this logic came to mind of Aristotle and some axioms of $\mathbf{T}$ were considered in his book

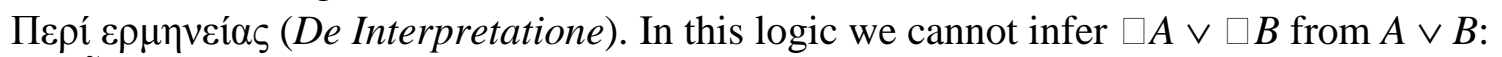

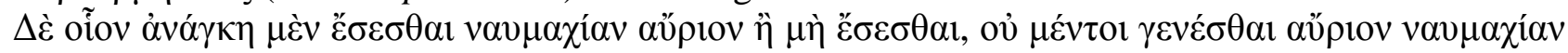

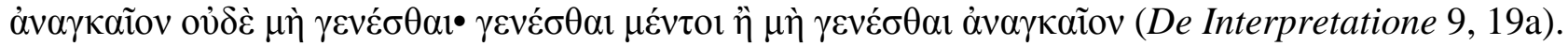

Necesse est quidem futurum esse bellum navale cras vel non esse futurum sed non futurum esse cras bellum navale necesse est vel non futurum esse, futurum autem esse vel non esse necesse est (De Interpretatione 9, 19a).

A sea-fight must either take place tomorrow or not, but it is not necessary that it should take place tomorrow, neither is it necessary that it should not take place, yet it is necessary that it either should or should not take place tomorrow.

Otherwise we should accept that $\diamond A \Rightarrow A$ is ever false and $A \Rightarrow \square A$ is ever true. But it is

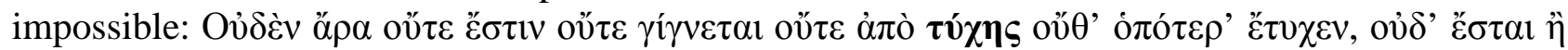

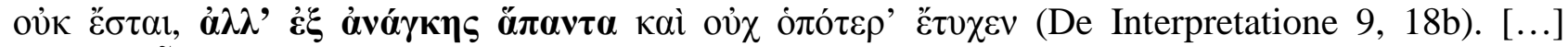

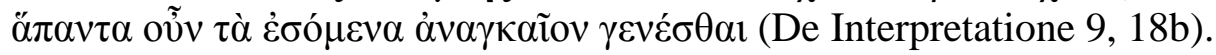

Nihil igitur neque est neque fit nec a casu nec utrumlibet, nec erit nec non erit sed ex necessitate omnia et non utrumlibet (De Interpretatione 9, 18b). [...] Omnia ergo quae futura sunt necesse est fiery (De Interpretatione $9,18 \mathrm{~b}$ ).

Then nothing is or takes place occasionally, either in the present or in the future, and there are no real alternatives; everything takes place of necessity and not occasionally [...]. [...] Then all that is to be must necessarily take place in the future.

The point is that Aristotle assumes the existence of logical contingency ( $\dot{\varepsilon} v \delta \varepsilon \chi o ́ \mu \varepsilon v o v)$. For example, propositions such as 'A sea-fight will be tomorrow' $(A)$ are logically contingent: $\diamond A \wedge$

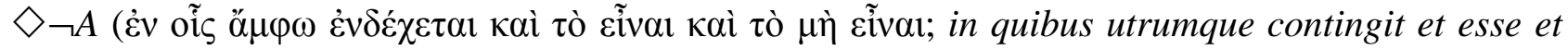
non esse). These statements can be true by some valuations in $\mathbf{T}$. 


\section{Modal Logic for Logical Determinacy}

So, systems $\mathbf{D}$ and $\mathbf{T}$ are used for explicating logical contingency within a modal logic. Nevertheless, we can explicate logical determinacy within a modal logic, too. For this purpose, we should involve other schemas added to $\mathbf{K}$ [2]:

(CD) $\diamond A \Rightarrow \square A$

(=) $A \Rightarrow \square A$

If we add to $\mathbf{K}$ all the instances of (CD), then the new modal logic is denoted by $\mathbf{C D}$. At the same time, if we add to $\mathbf{K}$ all the instances of $(=)$, then the new modal logic is denoted by $\mathbf{K}=$. From $(=)$ we can infer (CD). It means that all the axioms of $\mathbf{C D}$ occur among axioms of $\mathbf{K}=$. The intuition for modal logics $\mathbf{C D}$ and $\mathbf{K}=$ was expressed by the Stoics (first of all, by Chrysippus):

Nihil enim fieri sine causa potest (Cicero: De Divinatione 2, 61).

Nothing happens without a cause.

Motum nullum esse sine causa (Cicero: De Fato 23).

No motion is without a cause.

It means that each proposition is necessarily true or necessarily false because of causes existed for all events described by propositions. So, the proposition 'A sea-fight will take place tomorrow' is either necessarily true or necessarily false right now, since there are or there are not causes for the event to be a sea-fight tomorrow right now. Some Stoic synonyms for the word

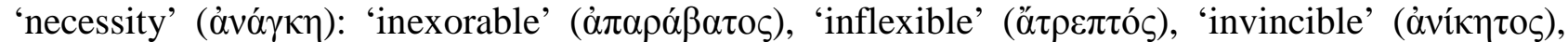

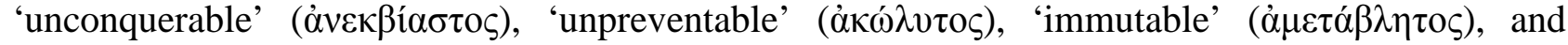

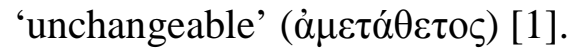

In the logic of $\mathbf{K}=$, the statement of contingency $\diamond A \wedge \diamond \neg A$ is always false, because the statement of determinacy $\square A \vee \square \neg A$ (the negation of $\diamond A \wedge \diamond \neg A$ ) is directly delivered from (CD) as an axiom.Hence, for logical contingency we deal with modal logic $\mathbf{T}$ and for logical determinacy we deal with logic $\mathbf{K}=$.

\section{Three-valued Logic for Logical Contingency}

In his famous paper On Three-Valued Logic [3], Jan Łukasiewicz was mainly inspirited by the

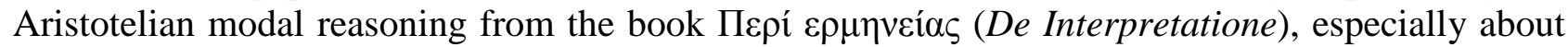
sea-fights tomorrow. In order to describe logical contingency, Łukasiewicz decided to introduce the third truth value $1 / 2$ with the meaning 'possible'. So, in his logic there are the following truth values: 0 ('false), 1 ('true'), $1 / 2$ ('possible'), where 1 is the designated truth value. The intuition for this introducing was as follows. The value 0 was understood as 'necessary false', the value 1 as 'necessary true', and the new value $1 / 2$ as 'possible'. In the meanwhile, $0<1 / 2<1$ so that we have the true implication $1 / 2 \Rightarrow 1$ which corresponds to axiom $(\mathrm{CD})$.

In this logic the meanings of propositional connectives are defined as follows:

Negation

\begin{tabular}{|l|l|}
\hline$A$ & $\neg A$ \\
\hline 1 & 0 \\
\hline $1 / 2$ & $1 / 2$ \\
\hline 0 & 1 \\
\hline
\end{tabular}




\section{Conjunction}

\begin{tabular}{|l|l|l|}
\hline$A$ & $B$ & $A \wedge B$ \\
\hline 1 & 1 & 1 \\
\hline 1 & $1 / 2$ & $1 / 2$ \\
\hline 1 & 0 & 0 \\
\hline $1 / 2$ & 1 & $1 / 2$ \\
\hline $1 / 2$ & $1 / 2$ & $1 / 2$ \\
\hline $1 / 2$ & 0 & 0 \\
\hline 0 & 1 & 0 \\
\hline 0 & $1 / 2$ & 0 \\
\hline 0 & 0 & 0 \\
\hline
\end{tabular}

\section{Disjunction}

\begin{tabular}{|l|l|l|}
\hline$A$ & $B$ & $A \wedge B$ \\
\hline 1 & 1 & 1 \\
\hline 1 & $1 / 2$ & 1 \\
\hline 1 & 0 & 1 \\
\hline $1 / 2$ & 1 & 1 \\
\hline $1 / 2$ & $1 / 2$ & $1 / 2$ \\
\hline $1 / 2$ & 0 & $1 / 2$ \\
\hline 0 & 1 & 1 \\
\hline 0 & $1 / 2$ & $1 / 2$ \\
\hline 0 & 0 & 0 \\
\hline
\end{tabular}

\section{Implication}

\begin{tabular}{|l|l|l|}
\hline$A$ & $B$ & $\begin{array}{l}A \\
B\end{array}$ \\
\hline 1 & 1 & 1 \\
\hline 1 & $1 / 2$ & $1 / 2$ \\
\hline 1 & 0 & 0 \\
\hline $1 / 2$ & 1 & 1 \\
\hline $1 / 2$ & $1 / 2$ & 1 \\
\hline $1 / 2$ & 0 & $1 / 2$ \\
\hline 0 & 1 & 1 \\
\hline 0 & $1 / 2$ & 1 \\
\hline 0 & 0 & 1 \\
\hline
\end{tabular}

According to these truth valuations, the law of excluded middle $A \vee \neg A$ is not an axiom. Indeed, its truth valuation does not give only truths:

\begin{tabular}{|l|l|l|}
\hline$A$ & $\neg A$ & $\begin{array}{l}A \vee \\
\neg A\end{array}$ \\
\hline 1 & 0 & 1 \\
\hline $1 / 2$ & $1 / 2$ & $1 / 2$ \\
\hline 0 & 1 & 1 \\
\hline
\end{tabular}


The law of contradiction $A \wedge \neg A$ has not only falsehood in this logic:

\begin{tabular}{|l|l|l|}
\hline$A$ & $\neg A$ & $\begin{array}{l}A \wedge \\
\neg A\end{array}$ \\
\hline 1 & 0 & 0 \\
\hline $1 / 2$ & $1 / 2$ & $1 / 2$ \\
\hline 0 & 1 & 0 \\
\hline
\end{tabular}

In this logic we can define two modal operators: $\square$ (“... is necessarily”) and $\diamond$ (“... is possibly”), as follows:

\begin{tabular}{|l|l|}
\hline$A$ & $\square A$ \\
\hline 1 & 1 \\
\hline $1 / 2$ & 0 \\
\hline 0 & 0 \\
\hline
\end{tabular}

\begin{tabular}{|l|l|}
\hline$A$ & $\diamond A$ \\
\hline 1 & 1 \\
\hline $1 / 2$ & 1 \\
\hline 0 & 0 \\
\hline
\end{tabular}

From both truth tables, it follows that (D) and (T) are axioms of Łukasiewisz's three-valued logic. Hence, Łukasiewicz supports the Aristotelian approach to logical modalities and, therefore, shares the Aristotelian ideas of logical contingency. Nevertheless, we can construct many-valued systems for the Stoic approach focused on logical determinacy.

\section{Four-valued Logic for Logical Determinacy}

Let us introduce the following four truth values: 0 ('possibly false), 1 ('necessarily false'), 2 ('possibly true'), 3 ('necessarily true'), where the designated truth value is represented by two values: 2 and 3. The intuition for these values is based on the following inequalities: $0<1<2<3$ so that we have the true implications $0 \Rightarrow 1$ and $2 \Rightarrow 3$ which correspond to axiom (CD). Now let us define propositional connectives on these values:

\section{Negation}

\begin{tabular}{|l|l|}
\hline$A$ & $\neg A$ \\
\hline 3 & 0 \\
\hline 2 & 1 \\
\hline 1 & 2 \\
\hline 0 & 3 \\
\hline
\end{tabular}

\section{Conjunction}

\begin{tabular}{|l|l|l|}
\hline$A$ & $B$ & $A \wedge B$ \\
\hline 3 & 3 & 3 \\
\hline 3 & 2 & 2 \\
\hline 3 & 1 & 1 \\
\hline 3 & 0 & 0 \\
\hline 2 & 3 & 2 \\
\hline 2 & 2 & 2 \\
\hline
\end{tabular}




\begin{tabular}{|l|l|l|}
\hline 2 & 1 & 1 \\
\hline 2 & 0 & 0 \\
\hline 1 & 3 & 1 \\
\hline 1 & 2 & 1 \\
\hline 1 & 1 & 1 \\
\hline 1 & 0 & 0 \\
\hline 0 & 3 & 0 \\
\hline 0 & 2 & 0 \\
\hline 0 & 1 & 0 \\
\hline 0 & 0 & 0 \\
\hline
\end{tabular}

\section{Disjunction}

\begin{tabular}{|l|l|l|}
\hline$A$ & $B$ & $A \vee B$ \\
\hline 3 & 3 & 3 \\
\hline 3 & 2 & 3 \\
\hline 3 & 1 & 3 \\
\hline 3 & 0 & 3 \\
\hline 2 & 3 & 3 \\
\hline 2 & 2 & 2 \\
\hline 2 & 1 & 2 \\
\hline 2 & 0 & 2 \\
\hline 1 & 3 & 3 \\
\hline 1 & 2 & 2 \\
\hline 1 & 1 & 1 \\
\hline 1 & 0 & 1 \\
\hline 0 & 3 & 3 \\
\hline 0 & 2 & 2 \\
\hline 0 & 1 & 1 \\
\hline 0 & 0 & 0 \\
\hline
\end{tabular}

\section{Implication}

\begin{tabular}{|l|l|l|}
\hline$A$ & $B$ & $A \vee B$ \\
\hline 3 & 3 & 3 \\
\hline 3 & 2 & 2 \\
\hline 3 & 1 & 1 \\
\hline 3 & 0 & 0 \\
\hline 2 & 3 & 3 \\
\hline 2 & 2 & 3 \\
\hline 2 & 1 & 2 \\
\hline 2 & 0 & 1 \\
\hline 1 & 3 & 3 \\
\hline 1 & 2 & 3 \\
\hline 1 & 1 & 3 \\
\hline 1 & 0 & 2 \\
\hline 0 & 3 & 3 \\
\hline 0 & 2 & 3 \\
\hline 0 & 1 & 3 \\
\hline 0 & 0 & 3 \\
\hline
\end{tabular}


In the four-valued logic with the two designated truth values: 2 and 3 , the law of excluded middle $A$ $\vee \neg A$ is an axiom. We can check it:

\begin{tabular}{|l|l|l|}
\hline$A$ & $\neg A$ & $\begin{array}{l}A \vee \\
\neg A\end{array}$ \\
\hline 3 & 0 & 3 \\
\hline 2 & 1 & 2 \\
\hline 1 & 2 & 2 \\
\hline 0 & 3 & 3 \\
\hline
\end{tabular}

The law of contradiction $A \wedge \neg A$ cannot take the two designated truth values:

\begin{tabular}{|l|l|l|}
\hline$A$ & $\neg A$ & $\begin{array}{l}A \wedge \\
\neg A\end{array}$ \\
\hline 3 & 0 & 0 \\
\hline 2 & 1 & 1 \\
\hline 1 & 2 & 1 \\
\hline 0 & 3 & 0 \\
\hline
\end{tabular}

The two modal operators: $\square$ (“... is necessarily”) and $\diamond$ (“... is possibly”) are understood as follows:

\begin{tabular}{|l|l|}
\hline$A$ & $\square A$ \\
\hline 3 & 3 \\
\hline 2 & 3 \\
\hline 1 & 1 \\
\hline 0 & 1 \\
\hline
\end{tabular}

\begin{tabular}{|l|l|}
\hline$A$ & $\diamond A$ \\
\hline 3 & 2 \\
\hline 2 & 2 \\
\hline 1 & 0 \\
\hline 0 & 0 \\
\hline
\end{tabular}

So, the necessity operator preserves the value 3 ('necessarily true') and 1 ('necessarily false') and makes 3 ('necessarily true') from 2 ('possibly true') and makes 1 ('necessarily false') from 0 ('possibly false'). The possibility operator preserves the value 2 ('possibly true') and 0 ('possibly false') and makes 2 ('possibly true') from 3 ('necessarily true') and makes 0 ('possibly false') from 1 ('necessarily false').

Thus, (CD) and (=) are axioms of the new logic:

\begin{tabular}{|l|l|l|l|}
\hline$A$ & $\diamond A$ & $\square A$ & $\begin{array}{l}\diamond A \\
\square A\end{array}$ \\
\hline 3 & 2 & 3 & 3 \\
\hline 2 & 2 & 3 & 3 \\
\hline 1 & 0 & 1 & 3 \\
\hline 0 & 0 & 1 & 3 \\
\hline
\end{tabular}




\begin{tabular}{|l|l|l|}
\hline$A$ & $\square A$ & $A \Rightarrow \square A$ \\
\hline 3 & 3 & 3 \\
\hline 2 & 3 & 3 \\
\hline 1 & 1 & 3 \\
\hline 0 & 1 & 3 \\
\hline
\end{tabular}

As we see, this logic is one of the possible formalizations of the Stoic idea of logical determinacy.

\section{Conclusion}

In developing many-valued logics, Łukasiewicz was highly inspirited by the Aristotelian modal approach towards logical contingency, although there is possible an alternative approach put forward by the Stoics towards logical determinacy. Within the Stoic approach we can appeal to the many-valuedness, too. So, we can propose a four-valued logic with the following truth values: 0 ('possibly false), 1 ('necessarily false'), 2 ('possibly true'), 3 ('necessarily true'), where the designated truth value is represented by the two values: 2 and 3 .

\section{References}

1. Bobzien, S. Determinism and Freedom in Stoic Philosophy, Oxford: Clarendon Press, 1998.

2. Garson, J. W. Modal Logic for Philosophers, Cambridge: Cambridge University Press, 2006.

3. Łukasiewicz, J. O logice trójwartościowej, Ruch filozoficzny 5, 1920, pp. 170-1716; English translation: On three-valued logic, In L. Borkowski (ed.), Selected works by Jan Łukasiewicz, Amsterdam: North-Holland, 1970, pp. 87-88. 